\title{
NUCLEAR DATA FOR CRITICALITY SAFETY - CURRENT ISSUES
}

\author{
L. C. Leal, W. C. Jordan, and R. Q. Wright
}

Computational Physics and Engineering Division

Oak Ridge National Laboratory ${ }^{\dagger}$

P.O. Box 2008

Oak Ridge, Tennessee $37831-6370$

To be presented at

Nuclear Criticality Technology and Safety Project

Embedded Topical Meeting

Catamaran Hotel

San Diego, California

May 17, 1995

The submilled manuscript tas been authored by a

contractor of the U.S. Government under contract No.

DR-AC05-840R21400. Acoordingly, the U.S.

Government retelns a noperciusive, roysity-free license

to publish or reproduce the published form of thls

contribution, or allow octhers to do 20 , for U.S.

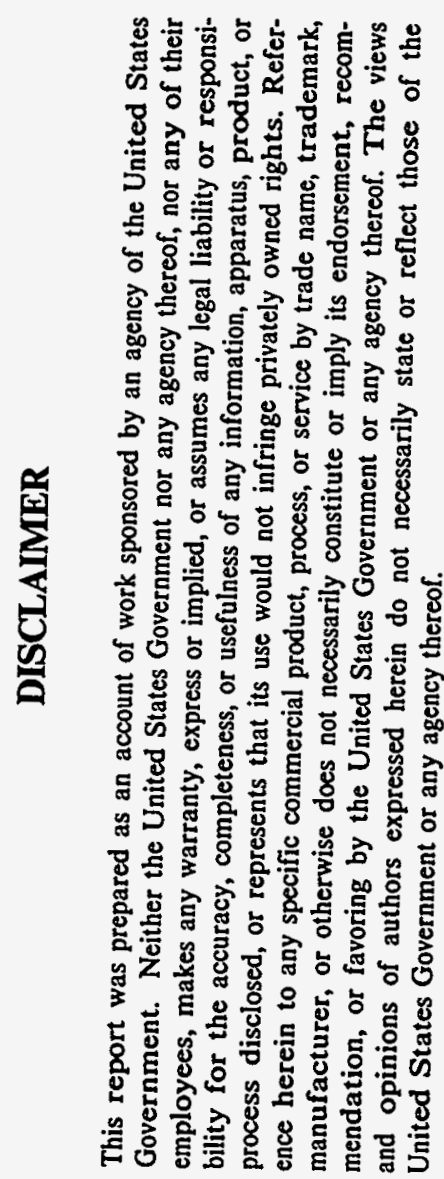

\footnotetext{
${ }^{\dagger}$ Managed by Martin Marietta Energy Systems, Inc., under contract DE-AC05-84OR21400 with the U.S. Department of Energy.
} 


\begin{abstract}
"quəunoop

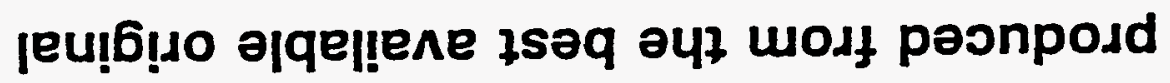

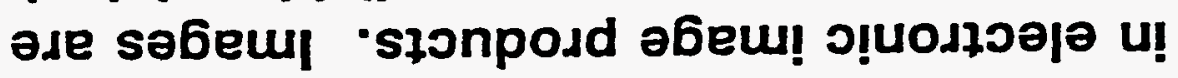

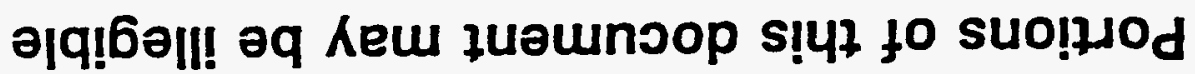

yヨWIชาอSI0
\end{abstract}




\title{
NUCLEAR DATA FOR CRITICALITY SAFETY - CURRENT ISSUES
}

\author{
L. C. Leal, W. C. Jordan, and R. Q. Wright
}

\section{INTRODUCTION}

Traditionally, nuclear data evaluations have been performed in support of the analysis and design of thermal and fast reactors. In general, the neutron spectra characteristic of the thermal and fast systems used for data testing are predominantly in the low- and high-energy range with a relatively small influence from the intermediate-energy range. In the area of nuclear criticality safety, nuclear systems arising from applications involving fissionable materials outside reactors can lead to situations very different from those most commonly found in reactor analysis and design. These systems are not limited to thermal or fast and may have significant influence from the intermediate energy range. The extension of the range of applicability of the nuclear data evaluation beyond thermal and fast systems is therefore needed to cover problems found in nuclear criticality safety.

Before criticality safety calculations are performed, the bias and uncertainties of the codes and cross sections that are used must be determined. The most common sources of uncertainties, in general, are the calculational methodologies and the uncertainties related to the nuclear data, such as the microscopic cross sections, entering into the calculational procedure. The aim here is to focus on the evaluated nuclear data pertaining to applications in nuclear criticality safety.

\section{CURRENT ISSUES}

In the winter of 1993, an article ${ }^{1}$ in the Criticality Safety Quarterly pointed out differences in the calculated infinite multiplication factor $\left(k_{\infty}\right)$ of calculations performed with the SCALE code system $^{2}$ and the MCNP code. ${ }^{3}$ The systems considered in the calculations were fictitious mixtures made of metal mixed with ${ }^{235} \mathrm{U}$, namely, $\mathrm{Al}^{235} \mathrm{U}, \mathrm{Fe} /{ }^{235} \mathrm{U}$, and $\mathrm{Zr}{ }^{235} \mathrm{U}$. Since the MCNP calculational methodology is based on the continuum energy approach, an assumption was made that the MCNP results were correct. In the absence of experimental data for these metal ${ }^{235} \mathrm{U}$ systems, to understand the cause of the discrepancies between the results, it was decided to calculate the $k_{\infty}$ of the metal/ ${ }^{235} \mathrm{U}$ systems using a variety of computer codes and cross-section libraries. It turned out that the $\mathrm{k}_{\infty}$ results of these calculations were not in agreement with MCNP. Since several sources of uncertainties contribute to the overall uncertainty in the integral results, the lack of agreement among the different calculational methodologies led us to investigate the methods and data used in the calculations. A detailed examination of the MCNP results suggested that the pointwise cross-section data of its library used in the calculations were not adequate for the systems under consideration. In particular, it was discovered that the aluminum cross sections in the ENDF library were given as averaged smooth cross sections which cannot be energy self-shielded even though aluminum has resonance structure. It is well known that resonance parameter representations are needed to properly account for resonance self-shielding effects. The neutron spectrum characterizing the $\mathrm{Al}^{235} \mathrm{U}$ system studied was in the intermediate energy range where the resonance self-shielding effects on the aluminum cross sections play an important role, and, therefore, strongly indicate the pointwise cross-section representation of ENDF/B is inadequate. In a separate study, a criticality safety assessment of the fuel cycle facility ${ }^{4}$ at Argonne National Laboratory, Idaho Falls, also indicates a similar problem related 


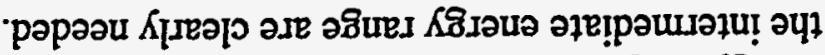

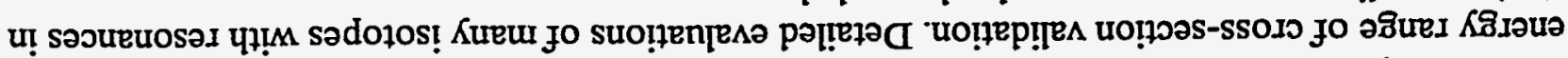

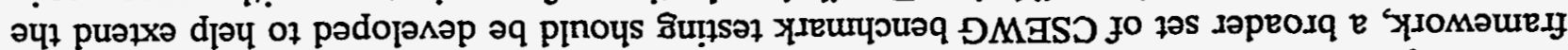

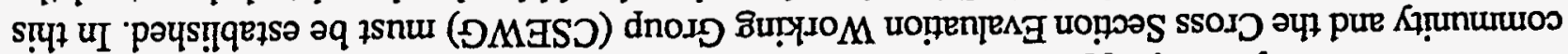

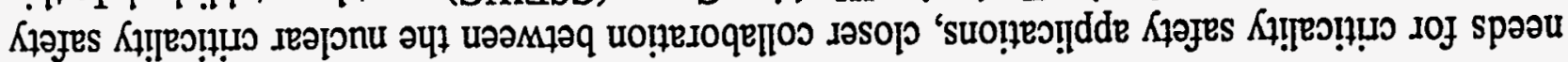

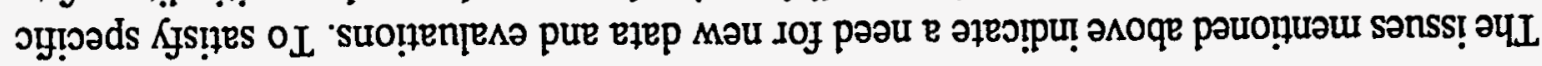

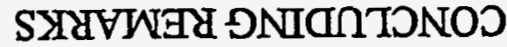

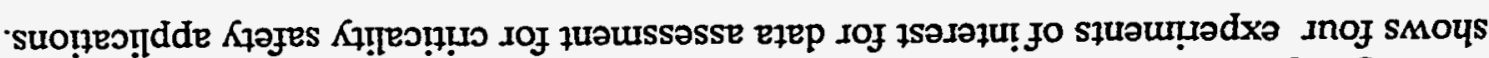

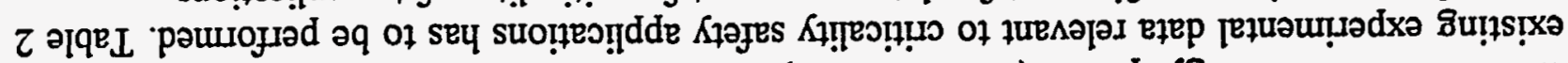

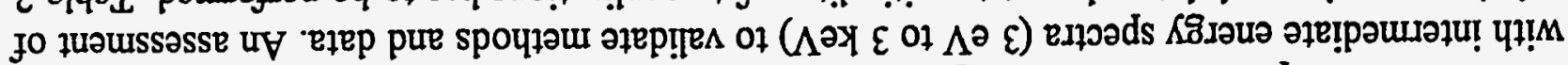

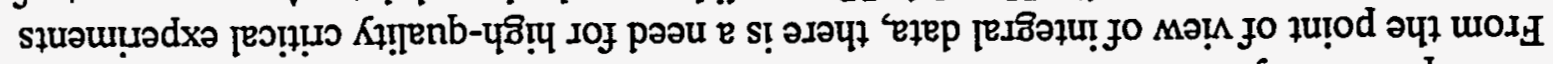

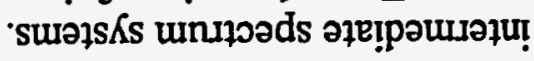

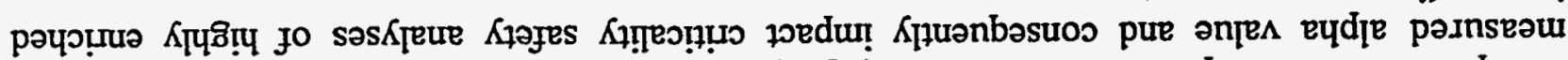

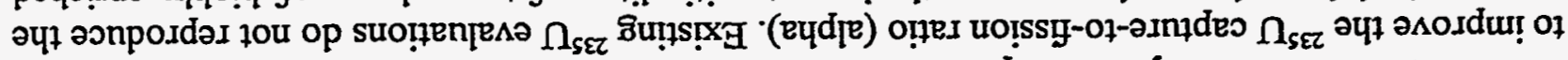

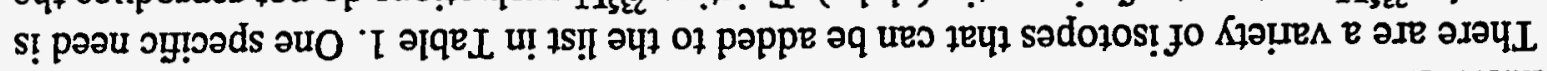

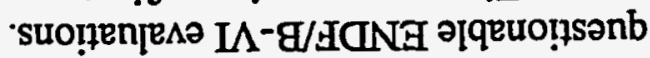

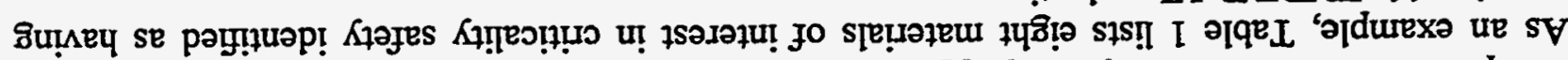

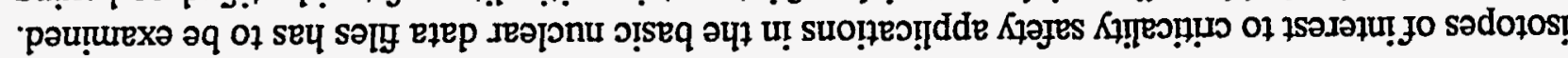

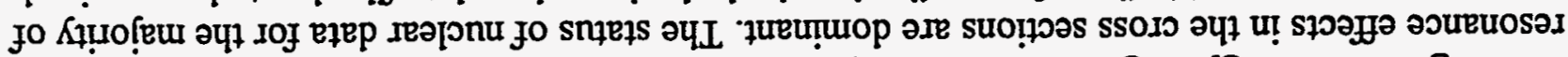

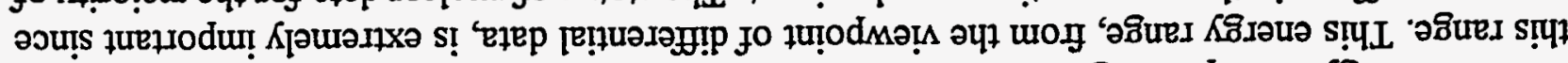

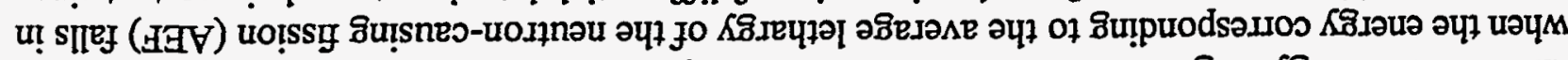

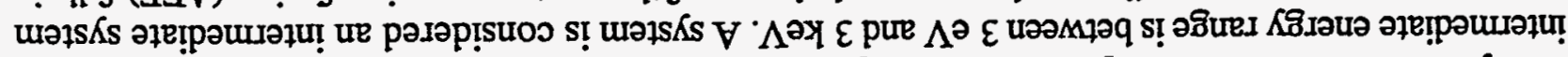

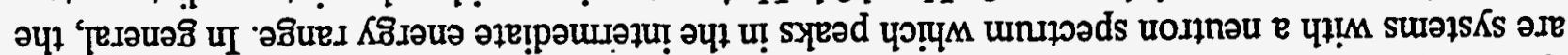

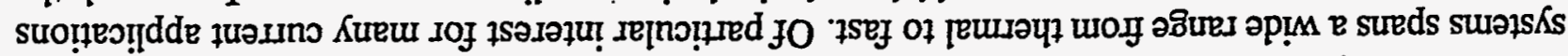

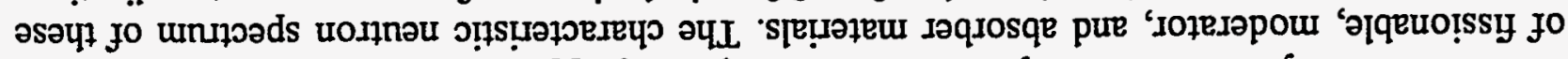

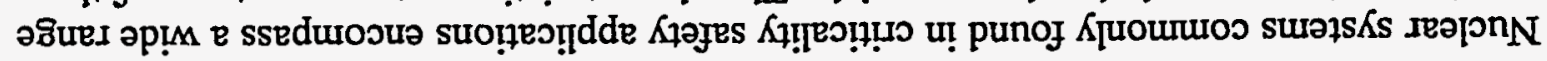

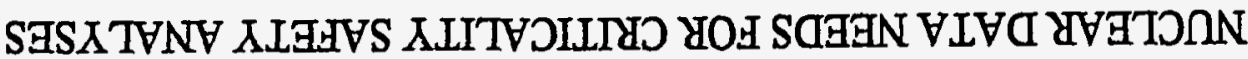

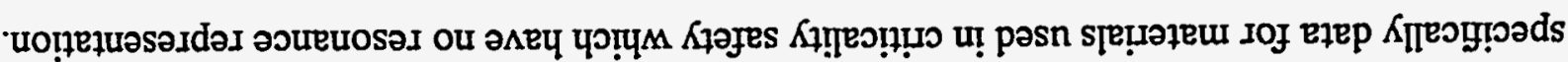

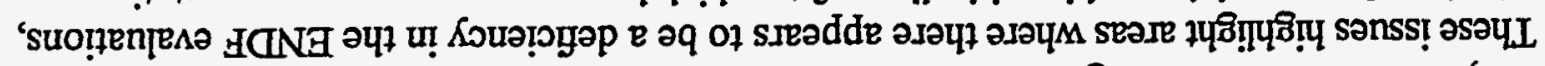

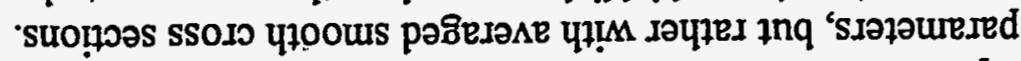

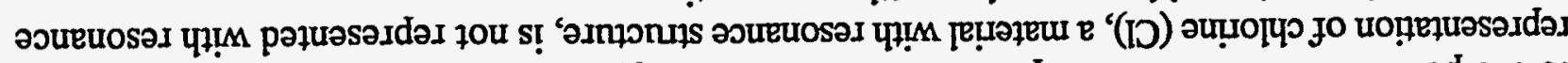

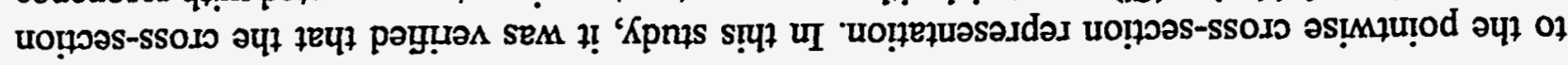


Table 1. Isotopes for which measurements and evaluations are needed

\begin{tabular}{|c|c|c|}
\hline \multirow{2}{*}{ Isotope } & \multicolumn{2}{|c|}{ Cross-section representation } \\
\cline { 2 - 3 } & Last evaluation & Resonance data \\
\hline${ }^{20} \mathrm{Ca}$ & Aug71 & No $^{\mathbf{2}}$ \\
\hline${ }^{27} \mathrm{Al}$ & Dec73 & No \\
\hline${ }^{17} \mathrm{Cl}$ & Feb67 & No $^{\mathbf{a}}$ \\
\hline${ }^{19} \mathrm{~K}$ & Feb67 & No $^{\mathbf{a}}$ \\
\hline${ }^{31} \mathrm{P}$ & Oct77 & No \\
\hline${ }^{14} \mathrm{Si}$ & Feb74 & No $^{\mathbf{2}}$ \\
\hline${ }^{12} \mathrm{Mg}$ & Feb78 & No $^{\mathbf{a}}$ \\
\hline${ }^{233} \mathrm{U}$ & Dec78 & Yes $^{2}$ \\
\hline
\end{tabular}

${ }^{2}$ Isotopic evaluations needed.

Table 2. Critical experiments with intermediate energy spectra

\begin{tabular}{|c|c|}
\hline Critical experiments & Description \\
\hline HISS(HUG) & Homogeneous uranium-graphite \\
\hline HISS(HPG) & Homogeneous plutonium-graphite \\
\hline $\mathrm{UH}_{3}-\mathrm{UR}$ & $\begin{array}{c}\text { High-enriched uranium with low-enriched } \\
\text { uranium reflector }\end{array}$ \\
\hline PCTR & Low-enriched $\mathrm{UO}_{3} / \mathrm{H}_{2} \mathrm{O}$ with a range of $\mathrm{H} / \mathrm{U}$ \\
\hline
\end{tabular}

\section{REFERENCES}

1. Palmer, B., " $\mathrm{k}_{\mathrm{w}}$ for Certain Metals Mixed with ${ }^{235} \mathrm{U}$," Criticality Safety Quarterly, Sponsored by DOE DO-62, Winter 1993.

2. SCALE: A Modular Code System for Performing Standardized Computer Analyses for Licensing Evaluation, NUREG/CR-0200, Rev. 4 (ORNL/NUREG/CSD-2R4), Vols. I, II, and III (November 1993). Available from Radiation Shielding Information Center at Oak Ridge National Laboratory as CCC-545. 
3. Briesmeister, J. F., Editor, MCNP: A General Monte Carlo Code for Neutron and Photon Transport, Version 3A, LA-7396-M, Rev. 2, Los Alamos National Laboratory, 1986.

4. Lell, R. M., et al., "Criticality Safety Evaluation of the Fuel Cycle Facility Electrorefiner," 1993 Topical Meeting on Physics and Methods in Criticality Safety, September 19-23, 1993, Nashville, Tennessee. 